\title{
The clinical significance of the incorporation of tissue Doppler imaging into low-dose Dobutamine stress echocardiography in patients with aortic stenosis prior to Transcatheter aortic valve implantation
}

\author{
Sahrai Saeed ${ }^{1 *+}\left(\mathbb{D}\right.$, Joerg Kellermair ${ }^{2+}$, Jon Herstad ${ }^{1}$ and Øyvind Bleie ${ }^{1}$
}

\begin{abstract}
Background: Low-dose dobutamine stress echocardiography (DSE) is indicated in patients with low flow (stroke volume index $[\mathrm{SVi}]<35 \mathrm{ml} / \mathrm{m}^{2}$ ) low gradient (mean pressure gradient $<40 \mathrm{mmHg}$ ) and left ventricular ejection fraction (LVEF) $<50 \%$ aortic stenosis (AS) to assess LV contractile reserve (> 20\% increase in SVi) and severity grade of AS. Severe AS is defined by a mean pressure gradient of $40 \mathrm{mmHg}$ occurring at any time during the test when aortic valve area remains $<1.0 \mathrm{~cm}^{2}$.

Case presentation: This case report highlights the utility of mitral annular systolic velocity (S') by tissue Doppler imaging and peak LV outflow tract (LVOT) velocity as markers of LV intrinsic contractile function during DSE in a patient with low flow low gradient AS and reduced EF prior to transcatheter aortic valve implantation (TAVI).
\end{abstract}

Conclusions: Mitral annular S' and peak LVOT velocities are reliable markers of LV intrinsic contractile function and should be incorporated into routine low-dose DSE.

Keywords: Aortic stenosis, Dobutamine-stress-echocardiography, Tissue Doppler, Mitral annular systolic velocity, Intrinsic contractile function

\section{Background}

This case is of clinical interest for physicians and sonographers who perform DSE in patient with classical low flow low gradient AS to assess contractile reserve, the patterns of flow normalization and the hemodynamic severity of AS. However, the incorporation of mitral

\footnotetext{
* Correspondence: sahrai.saeed@helse-bergen.no

${ }^{+}$Sahrai Saeed and Joerg Kellermair contributed equally to this work.

${ }^{1}$ Department of Heart Disease, Haukeland University Hospital, Jonas Lies vei 65, 5021 Bergen, Norway

Full list of author information is available at the end of the article
}

annular $\mathrm{S}^{\prime}$ and peak LVOT velocity into low dose DSE may provide additional information on the LV intrinsic contractile function and the potentials for recovery of $\mathrm{LV}$ function following valve intervention.

\section{Case presentation}

A 82-year-old male with known coronary artery disease (previous coronary artery bypass grafting following myocardial infarction), diabetes type II, hypertension and hypercholesterolemia, and smoking-induced chronic obstructive pulmonary disease (FEV1 69\%) was referred to

C The Author(s). 2020 Open Access This article is licensed under a Creative Commons Attribution 4.0 International License, which permits use, sharing, adaptation, distribution and reproduction in any medium or format, as long as you give appropriate credit to the original author(s) and the source, provide a link to the Creative Commons licence, and indicate if changes were made. The images or other third party material in this article are included in the article's Creative Commons licence, unless indicated otherwise in a credit line to the material. If material is not included in the article's Creative Commons licence and your intended use is not permitted by statutory regulation or exceeds the permitted use, you will need to obtain permission directly from the copyright holder. To view a copy of this licence, visit http://creativecommons.org/licenses/by/4.0/ The Creative Commons Public Domain Dedication waiver (http://creativecommons.org/publicdomain/zero/1.0/) applies to the data made available in this article, unless otherwise stated in a credit line to the data. 
our heart valve clinic for assessment of AS. An echocardiogram 2 years earlier had shown LVEF of $60 \%$ and a moderate AS. He had experienced progressive dyspnea over the past 4 weeks (NYHA function class III).

His medications included vildagliptin $50 \mathrm{mg}$ twice daily, empagliflozin $25 \mathrm{mg}$ once daily (OD), liraglutid 1.2 $\mathrm{mg}$ s.c. OD, aclidinium bromide/formoterol fumarate dehydrate inhalation 340/12 $\mu \mathrm{g}$ twice daily, aspirin $75 \mathrm{mg}$ OD, metoprolol depot $50 \mathrm{mg}$ OD and atorvastatin $40 \mathrm{mg}$ OD.

His body surface area was $1.80 \mathrm{~m}^{2}$. On physical examination, there was a systolic murmur, grade $4 / 6$ on the right and left 2nd intercostal space, with the preserved second heart sound. His blood pressure was 124/79 mmHg.

\section{Investigations}

Laboratory tests: Apart from non-fasting serum glucose $(11.3 \mathrm{mmol} / \mathrm{L})$ and NT-pro-BNP $(260 \mathrm{ng} / \mathrm{L})$, all other blood tests were normal including troponin $\mathrm{T}(9 \mathrm{ng} / \mathrm{L})$, creatinine $(67 \mu \mathrm{mol} / \mathrm{L})$, eGFR $\left(67 \mathrm{~mL} / \mathrm{min} / 1.73 \mathrm{~m}^{2}\right)$, so$\operatorname{dium}(139 \mathrm{mmol} / \mathrm{L})$ and potassium $(4.3 \mathrm{mmol} / \mathrm{L})$.

Chest X-ray was unremarkable.

Coronary angiography showed a normal left main stem, native three-vessel disease, but open coronary bypass grafts (left internal mammillary artery to left anterior descending artery, and saphenous vein grafts to circumferential artery and right coronary artery). No new obstructive lesions were revealed. Heart CT showed a tricuspid aortic valve with Ca score of 2140 Agatston units.

An ECG showed sinus rhythm with heart rate of 58 beat per minute, and a Q-wave in leads II, III and AVF.

\section{Echocardiography}

Conventional echocardiography (Philips "Epiq 7"; Philips Medical Systems, Bothell, WA) showed reduced LVEF $(42 \%)$ and hypokinesia in the ventricular septum and inferior wall following previous myocardial infarction. The Aortic valve was heavily calcified (Fig. 1). Flow rate was $168 \mathrm{ml} / \mathrm{s}$ and stroke volume index (SVi) $32 \mathrm{ml} / \mathrm{m}^{2}$. AS was mild by peak aortic jet-velocity $(2.6 \mathrm{~m} / \mathrm{s})$, but severe by aortic valve area $\left(0.9 \mathrm{~cm}^{2}\right)$. A mild aortic and mitral regurgitations were noted. There was no sign of rightsided valvular heart disease or pulmonary hypertension. A low-dose DSE (3 min stages with a starting dose $5 \mu \mathrm{g}$ / $\mathrm{kg} / \mathrm{min}$ increasing to 10,15 and $20 \mu \mathrm{g} / \mathrm{kg} / \mathrm{min}$ ) was indicated to assess contractile reserves and the severity grade of AS, i.e. differentiate true severe from pseudo-severe [1]. The main results of DSE are reported in Table 1. Briefly, SVi increased from $32 \mathrm{ml} / \mathrm{m}^{2}$ to $43 \mathrm{ml} / \mathrm{m}^{2}$ (34\% increase), aortic jet velocity from $2.6 \mathrm{~m} / \mathrm{s}$ to $3.4 \mathrm{~m} / \mathrm{s}$ and aortic valve area from $0.93 \mathrm{~cm}^{2}$ to $1.07 \mathrm{~cm}^{2}$. LVEF increased from 42 to $50 \%$, peak LVOT velocity from 0.69 $\mathrm{m} / \mathrm{s}$ to $1.04 \mathrm{~m} / \mathrm{s}$ (51\% increase), septal mitral annular $\mathrm{S}^{\prime}$ from $6 \mathrm{~cm} / \mathrm{s}$ to $8 \mathrm{~cm} / \mathrm{s}$ (33\% increase) and lateral mitral annular $\mathrm{S}^{\prime}$ from $7 \mathrm{~cm} / \mathrm{s}$ to $12 \mathrm{~cm} / \mathrm{s}$ (71\% increase) (Table 1 and Figs. 2 and 3).

\section{Treatment and outcome}

This patient with AS, LV dysfunction and coronary artery disease who appeared to be increasingly symptomatic with NYHA function class III for four weeks prior to the admission, underwent a coronary angiography which did not reveal any new flow-limiting lesions requiring percutaneous coronary intervention or explaining the increase in symptoms. A low-dose DSE revealed adequate contractile reserves and a moderate to severe
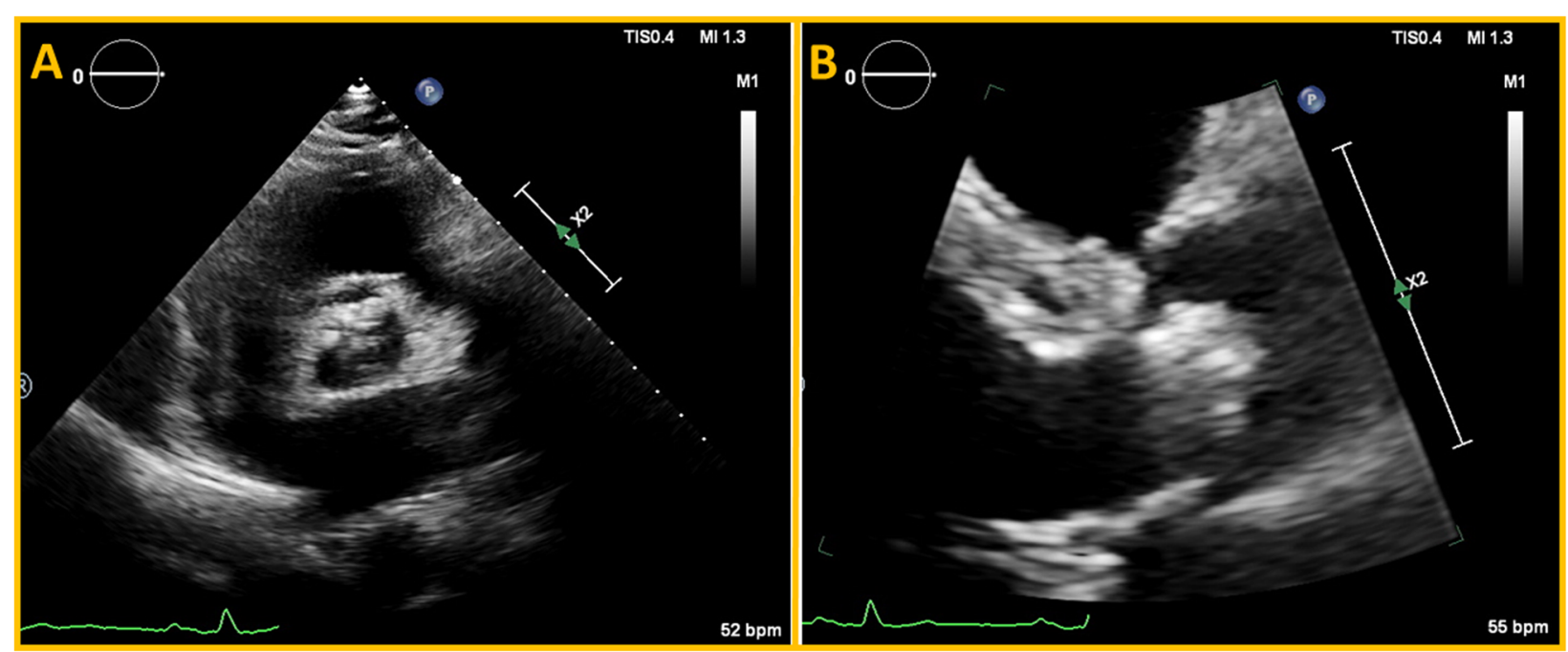

Fig. 1 Aortic valve calcification in parasternal short axis (a) and long axis views (b) 
Table 1 Measures of resting and low-dose dobutamine stress echocardiography in a patient with low flow, low gradient, low EF aortic stenosis

\begin{tabular}{|c|c|c|c|c|c|}
\hline Echocardiographic parameters & Resting & $\begin{array}{l}\text { Stage I } \\
5 \mu / \mathrm{kg} / \mathrm{min}\end{array}$ & $\begin{array}{l}\text { Stage II } \\
10 \mu / \mathrm{kg} / \mathrm{min}\end{array}$ & $\begin{array}{l}\text { Stage III } \\
15 \mu / \mathrm{kg} / \mathrm{min}\end{array}$ & $\begin{array}{l}\text { Stage IV } \\
20 \mu / \mathrm{kg} / \mathrm{min}\end{array}$ \\
\hline Heart rate (beat per minute) & 52 & 54 & 53 & 55 & 60 \\
\hline Peak aortic jet velocity (m/s) & 2.6 & 2.6 & 3.0 & 3.0 & 3.4 \\
\hline Mean pressure gradient $(\mathrm{mmHg})$ & 16 & 17 & 22 & 22 & 26 \\
\hline Peak LVOT velocity (m/s) & 0.69 & 0.73 & 0.93 & 0.93 & 1.04 \\
\hline Aortic valve area $\left(\mathrm{cm}^{2}\right)$ & 0.93 & 0.82 & 1.02 & 1.06 & 1.07 \\
\hline Stroke volume index $\left(\mathrm{ml} / \mathrm{m}^{2}\right)$ & 32 & 31 & 39 & 40 & 43 \\
\hline Systolic ejection time (ms) & 346 & 343 & 322 & 323 & 300 \\
\hline Flow rate $(\mathrm{ml} / \mathrm{s})$ & 168 & 159 & 208 & 217 & 255 \\
\hline LV ejection fraction (\%) & 42 & NA & NA & NA & 50 \\
\hline Septal S' (cm/s) & 6 & NA & NA & NA & 8 \\
\hline Lateral annular S' (cm/s) & 7 & NA & NA & NA & 12 \\
\hline
\end{tabular}

Left ventricular outflow track (LVOT) diameter $2.1 \mathrm{~cm}$

AS, supported by a heavily calcified aortic valve as seen with heart CT. His symptoms and LV dysfunction were primarily attributed to AS. His medical treatment was optimised by adding an angiotensin-converting enzyme inhibitor. After discussion at the heart team, he was considered eligible for TAVI, and a SAPIEN 3 Ultra $^{\circ} 26 \mathrm{~mm}$ was successfully implanted transfemoraly 4 weeks after DSE without any complications. An echocardiogram at discharge showed decrease in mean aortic pressure gradient to $7 \mathrm{mmHg}$, increase in $\mathrm{SVi}$ to $35 \mathrm{ml} / \mathrm{m}^{2}$, peak LVOT velocity to $1 \mathrm{~m} / \mathrm{s}$ (Fig. 4), and LVEF to $50 \%$.
Septal $S^{\prime}$ increased to $8 \mathrm{~cm} / \mathrm{s}$ and lateral $S^{\prime}$ to $12 \mathrm{~cm} / \mathrm{s}$ (Fig. 3).

\section{Follow-up at 6-weeks following TAVI}

Patient's symptoms gradually improved within few weeks after TAVI. At 6 weeks follow-up he remained free of symptoms and systolic tissue Doppler velocities and peak LVOT velocity remained stable (the same values as at discharge). SVi further increased to $55 \mathrm{ml} / \mathrm{m}^{2}$ and peak LVOT velocity to $1.27 \mathrm{~m} / \mathrm{s}$.

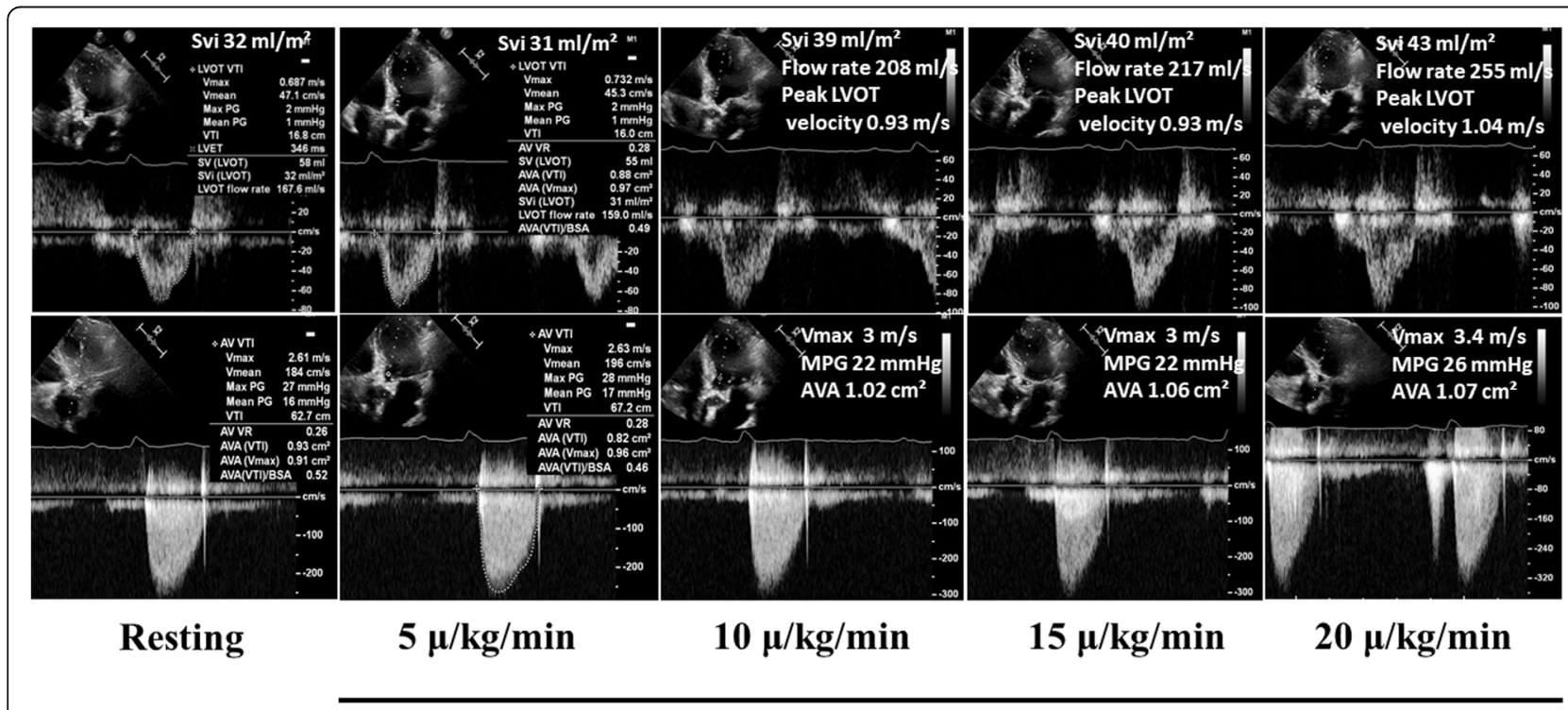

\section{Low dose dobutamine stress echocardiography}

Fig. 2 Changes in aortic flow, peak LVOT velocity, MPG, Vmax and AVA from rest to peak dobutamine stress echocardiography. AVA, aortic valve area; LVOT, left ventricular outflow tract; MPG, mean aortic pressure gradient; SVi, stroke volume index; Vmax, peak aortic jet velocity 


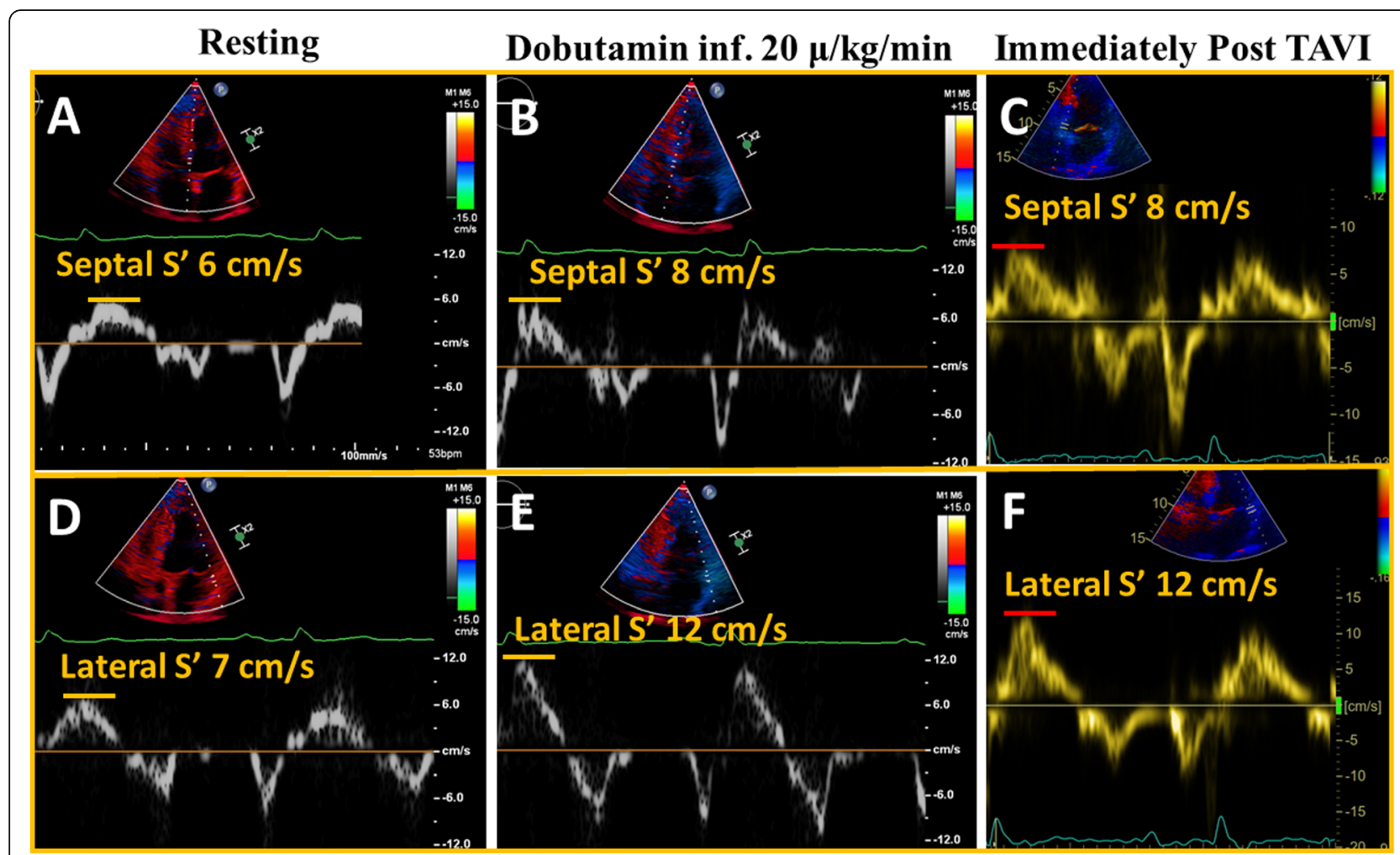

Fig. 3 Septal and lateral $S^{\prime}$ at rest $(\mathbf{a}, \mathbf{d})$, peak dobutamine stress echocardiography $(\mathbf{b}, \mathbf{e})$ and immediately after TAVI $(\mathbf{c}, \mathbf{f})$

\section{Discussion and conclusion}

In routine clinical practice, a low dose DSE is essential for subcategorization of classical low flow low gradient AS into true severe and pseudo-severe, and assessment of contractile reserves, reflected by $>20 \%$ increase in SVi. Low dose DSE is a relatively safe and tolerable investigation, and provides valuable information on LV contractile reserve, which has important implications in terms of surgical risk stratification [2,3]. During DSE several types of hemodynamic responses may be observed (Table 2) [1]. In our patient, a type B response was observed, suggesting that AS was per definition moderate (Tables 1 and 2). However, the aortic valve area at peak stress was $1.07 \mathrm{~cm}^{2}$, a borderline cut-off between moderate and severe. Aortic valve was heavily calcified with a Ca score of 2140 Agatston units by CT,

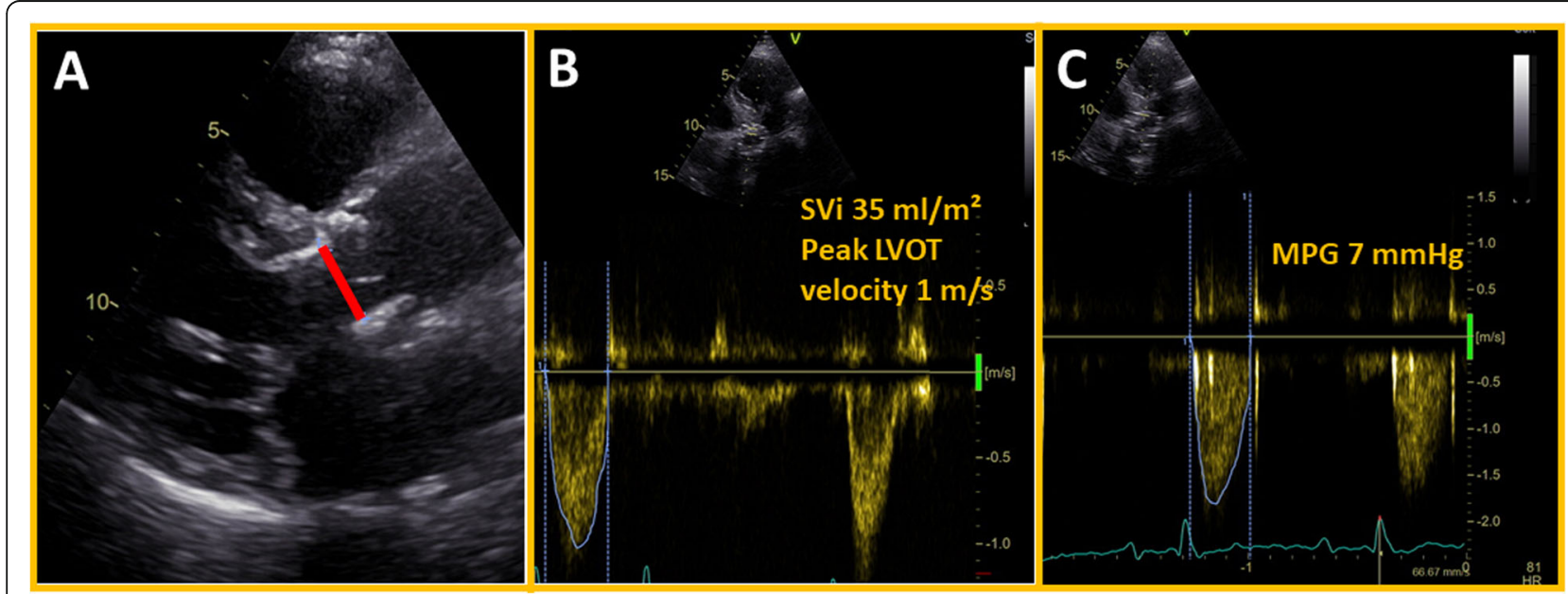

Fig. 4 Bioprosthesis in aortic position and annulus diameter (a), SVi and peak LVOT velocity (b) and MPG immediately after TAVI (C). LVOT, left ventricular outflow tract; MPG, mean aortic pressure gradient; SVi, stroke volume index 
Table 2 Types of hemodynamic response during low-dose DSE in patients with low flow (stroke volume index $<35 \mathrm{ml} / \mathrm{m}^{2}$ ), low gradient (mean pressure gradient $<40 \mathrm{mmHg}$ ) and low left ventricular ejection fraction $(<50 \%)$ severe aortic stenosis (aortic valve area $\left.<1.0 \mathrm{~cm}^{2}\right)$

\begin{tabular}{lllll}
\hline & Stroke volume and ejection fraction & Mean pressure gradient & Aortic valve area & Interpretation \\
\hline A & $\uparrow$ & $\uparrow$ & $\leftrightarrow$ & Severe AS \\
B & $\uparrow$ & $\leftrightarrow$ & $\uparrow$ & Moderate AS \\
C & $\leftrightarrow$ & $\leftrightarrow$ & $\leftrightarrow$ & Severe AS, severe LV dysfunction \\
\hline
\end{tabular}

AS aortic stenosis, LV left ventricular, DSE dobutamine stress echocardiography

indicating a hemodynamically severe AS. In order to restore LV function and treat symptoms, the removal of valvular resistance/stenosis by TAVI was essential. It is known that the prognosis of moderate AS is no longer benign [4]. In a recent large study of AS patients from Australia, the authors demonstrated that moderate and severe AS had equally high rates of mortality when left untreated [5]. We have recently shown that patients with moderate and severe AS had similar degree of aortic damage, as reflected by carotid-femoral pulse wave velocity [6].

LVEF and SVi are the conventional markers of heart pump function and may not necessarily reflect the true intrinsic contractile function of the LV. This case report illustrates that besides the traditional contractile reserves as assessed by $>20 \%$ increase in $\mathrm{SVi}$, other routine echocardiographic parameters such as mitral annular $S^{\prime}$ by tissue Doppler and peak LVOT velocity may also provide important clinical information on the recovery of LV function following valve intervention. During DSE, the septal $\mathrm{S}^{\prime}$ increased by $33 \%$ to $8 \mathrm{~cm} / \mathrm{s}$, lateral annular $\mathrm{S}^{\prime}$ by $71 \%$ to $12 \mathrm{~cm} / \mathrm{s}$, and peak LVOT velocity increased by $51 \%$ to $1.04 \mathrm{~m} / \mathrm{s}$ (Figs. 2 and 3). The same level of LV performance achieved by DSE was seen at rest immediate after TAVI. For comparison, SVi increased by $34 \%$ to $43 \mathrm{ml} / \mathrm{m}^{2}$ during DSE pre TAVI, remained at $35 \mathrm{ml} / \mathrm{m}^{2}$ post TAVI, but further increased to $55 \mathrm{ml} / \mathrm{m}^{2} 6$ weeks after TAVI. In a previous study of severe AS by Lindqvist et al. septal annular $\mathrm{S}^{\prime}$ increased from $5.8 \mathrm{~cm} / \mathrm{s}$ before TAVI to $7.0 \mathrm{~cm} / \mathrm{s} 1$ week after TAVI, and remained largely unchanged 6 months after TAVI $(7.2 \mathrm{~cm} / \mathrm{s})$ [7]. In our patient we observed a similar response at 6-weeks follow-up.

Both Tissue Doppler S' and peak LVOT velocities are easy to measure during routine echocardiography. Tissue Doppler $S^{\prime}$ is a robust marker of systolic LV function, particularly in the longitudinal axis, and correlates well with strain and markers of myocardial fibrosis such as late gadolinium enhancement on cardiac MR [8]. Reduced long-axis function, as reflected by $S^{\prime}$ is common in AS patients who are often older ( $>65$ years) and have concomitant comorbidities such as hypertension and increased arterial stiffness [9]. However, a significant increase in $\mathrm{S}^{\prime}$ during DSE in AS patients with LV dysfunction may suggest that myocardial damage may be reversible and LV function can be restored following AVR, which was evident in our patient. Furthermore, although transaortic flow remained borderline $\left(35 \mathrm{ml} / \mathrm{m}^{2}\right)$ immediately after TAVI, it further increased to $55 \mathrm{ml} / \mathrm{m}^{2}$ at 6-weeks follow-up, which indicates early reverse LV remodeling. Mitral annular S' may be a better immediate marker of LV recovery after pressure unloading compared with SVi. However, this is our experience from this particular case report and we therefore suggest that the clinical significance and prognostic value of mean change in mitral annular $\mathrm{S}^{\prime}$ and peak LVOT velocities from rest to peak stress in patients with low flow low gradient AS should be explored in future prospective studies.

This case report demonstrates that mitral annular S' and peak LVOT velocities are reliable markers of LV intrinsic contractile function, correlate well with the indices of transaortic flow (SVi and flow rate) and may be true markers of LV recovery after unloading AS by TAVI.

We suggest the incorporation of tissue Doppler $S^{\prime}$ and LVOT velocities into routine low-dose DSE.

\section{Abbreviations}

AS: Aortic stenosis; CT: Computed tomography; DSE: Dobutamine stress echocardiography; LV: Left ventricle; LVEF: Left ventricular ejection fraction; LVOT: Left ventricular outflow tract; NYHA: New York heart association; OD: Once daily; SVi: Stroke volume index; TAVI: Transcatheter aortic valve implantation

\section{Acknowledgements}

Not applicable.

\section{Authors' contributions}

S.S. and J.K. wrote the manuscript and collected the data. J.H. collected the data and drafted the manuscript in collaboration with S.S and J.K. $\varnothing . B$ revised the manuscript, contributed to the design of the work and supervised the project. All authors critically revised and approved the manuscript.

\section{Funding}

This research did not receive any specific grant from any funding agency in the public, commercial or not-for-profit sector.

Availability of data and materials

Data are available by the corresponding author upon reasonable request.

Ethics approval and consent to participate

Written informed consent was obtained from the patient with regard to publication of the submitted article and accompanying images. 


\section{Consent for publication}

The patient gave the explicit permission to use the clinical information and echocardiographic material for publication.

\section{Competing interests}

The authors declare that they have no competing interests.

\section{Author details}

'Department of Heart Disease, Haukeland University Hospital, Jonas Lies vei 65, 5021 Bergen, Norway. ${ }^{2}$ Department of Cardiology, Kepler University Hospital, Medical Faculty Johannes Kepler University Linz, Krankenhausstrasse 9, 4020 Linz, Austria.

Received: 4 July 2020 Accepted: 7 September 2020

Published online: 14 September 2020

References

1. Baumgartner H, Hung J, Bermejo J, Chambers JB, Edvardsen T, Goldstein S, et al. Recommendations on the echocardiographic assessment of aortic valve stenosis: a focused update from the European Association of Cardiovascular Imaging and the American Society of Echocardiography. J Am Soc Echocardiogr. 2017:30:372-92.

2. Monin JL, Quere JP, Monchi M, Petit H, Baleynaud S, Chauvel C, Pop C, Ohlmann P, Lelguen C, Dehant P, Tribouilloy C, Guéret P. Low gradient aortic stenosis: operative risk stratification and predictors for long-term outcome: a multicenter study using dobutamine stress hemodynamics. Circulation. 2003;108:319-24.

3. Levy F, Laurent M, Monin JL, Maillet JM, Pasquet A, Le Tourneau T, PetitEisenmann H, Gori M, Jobic Y, Bauer F, Chauvel C, Leguerrier A, Tribouilloy C. Aortic valve replacement for low-flow/low-gradient aortic stenosis operative risk stratification and long-term outcome: a European multicenter study. J Am Coll Cardiol. 2008;51:1466-72.

4. Chambers JB, Rajani R, Parkin D, Saeed S. Rapid early rise in heart rate on treadmill exercise in patients with asymptomatic moderate or severe aortic stenosis: a new prognostic marker? Open Heart. 2019 Jan 31:6(1):e000950.

5. Strange G, Stewart S, Celermajer D, Prior D, Scalia GM, Marwick T, Ilton M, Joseph M, Codde J. Playford D; National Echocardiography Database of Australia contributing sites. Poor long-term survival in patients with moderate aortic stenosis. J Am Coll Cardiol. 2019;74:1851-63.

6. Saeed S, Saeed N, Grigoryan K, Chowienczyk P, Chambers JB, Rajani R. Determinants and clinical significance of aortic stiffness in patients with moderate or severe aortic stenosis. Int J Cardiol. 2020;50167-5273(19): 36394-6.

7. Lindqvist $\mathrm{P}$, Bajraktari $\mathrm{G}$, Molle $\mathrm{R}$, Palmerini $\mathrm{E}$, Holmgren $\mathrm{A}$, Mondillo $\mathrm{S}$, et al. Valve replacement for aortic stenosis normalizes subendocardial function in patients with normal ejection fraction. Eur J Echocardiogr. 2010;11:608-13.

8. Saeed S, Dweck MR, Chambers J. Sex differences in aortic stenosis: from pathophysiology to treatment. Expert Rev Cardiovasc Ther. 2020;18:65-76.

9. Saeed S, Scalise F, Chambers JB, Mancia G. Hypertension in aortic stenosis: a focused review and recommendations for clinical practice. J Hypertens. 2020;38:1211-9.

\section{Publisher's Note}

Springer Nature remains neutral with regard to jurisdictional claims in published maps and institutional affiliations.

Ready to submit your research? Choose BMC and benefit from:
- fast, convenient online submission
- thorough peer review by experienced researchers in your field
- rapid publication on acceptance
- support for research data, including large and complex data types
- gold Open Access which fosters wider collaboration and increased citations
- maximum visibility for your research: over 100M website views per year
At BMC, research is always in progress.
Learn more biomedcentral.com/submissions

